\title{
Streptococci from primary isolation plates grouped by reverse passive haemagglutination
}

\author{
M Farrington, S Winters, D Rubenstein, J Greatorex, R Whetstone
}

\begin{abstract}
Reverse passive haemagglutination, a novel microtitre based assay, was compared with the Streptex (Wellcome UK) latex slide agglutination kit for streptococcal grouping in a diagnostic microbiology laboratory. Three hundred and fifty two extracts from 349 consecutive primary isolation plates were assayed by both methods. Reverse passive haemagglutination gave identical grouping results for $98 \cdot 0 \%$ of the 345 streptococci identified by Streptex, and the $\kappa$ coefficient of agreement between the methods for all 352 extracts tested was 0.973 . Cross reactions with Listeria spp seen with Streptex were not found by reverse passive haemagglutination. In the reverse passive haemagglutination method 11 streptococci could be grouped on each 96-well plate and most reactions were stable for at least $\mathbf{3 0}$ minutes.

Reverse passive haemagglutination is more rapid to perform than latex slide agglutination when many organisms are to be grouped, and the patterns of haemagglutination are easily recognised. If the method was taken into routine use in a diagnostic laboratory, the persistence of reverse passive haemagglutination reactions would enable grouping results to be checked for quality control purposes.
\end{abstract}

Grouping of $\beta$ haemolytic streptococci, which traditionally depends on time consuming and expensive capillary precipitation methods, is usually performed in diagnostic laboratories by one of the commercially available "coagglutination" (COA) or latex agglutination kits. ${ }^{1}$ Several publications attest to the specificity and sensitivity of these methods. ${ }^{2-9}$ Each test takes only a few minutes of technical time, although antigen extraction is usually required and specificity is reduced when agglutinations are performed on colonies from primary isolation plates. Skill is needed in the interpretation of the agglutination reactions, however, and none of the reported techniques gives the opportunity for batch or automated processing if large numbers of tests are to be undertaken. Furthermore, specific agglutination is a transient phenomenon that makes quality control of the results difficult to achieve.

Reverse passive haemagglutination $(\mathrm{RPH})^{1011}$ relies on the agglutination in microtitre trays of antibody coated red cells by specific antigen. Agglutinability has been optimised in some systems by prior treatment of the red cells with proteolytic enzymes, and long term stability of reagents can be achieved by glutaraldehyde stabilisation and freeze drying.

We have grouped clinical isolates from 349 consecutive primary isolation plates in a reverse passive haemagglutination assay with stabilised, freeze dried sheep erythrocytes coupled to Lancefield group specific antisera against streptococcal groups A, B, C, D, F and $\mathrm{G}$ (Wellcome Streptococcal Grouping Sera, ZJ series; Wellcome Diagnostic, Dartford, England). We compared the results with those obtained by the Streptex LA kit (Wellcome Diagnostics). Discrepant reactions were further investigated with the Phadebact Streptococcus slide COA system (Karo Bio Diagnostics, Sweden) and the API 20 Strep kit (BioMèrieux, France). ${ }^{7}$

\section{Methods}

PREPARATION OF STOCK REVERSE PASSIVE

HAEMAGGLUTINATION REAGENTS

Antibody coupled erythrocytes were prepared as follows: sheep red blood cells that had been washed in phosphate buffered saline (PBS) were incubated for 20 minutes at $37^{\circ} \mathrm{C}$ with $\alpha$ chymotrypsin in acidified PBS/azide complement fixation test buffer (BR16, Oxoid). Stock chromic chloride coupling solution was made by dissolving $\mathrm{CrCl}_{3} \cdot 6 \mathrm{H}_{2} \mathrm{O}(\mathrm{BDH}$, England) to a $1 \%$ concentration in pyrogenfree physiological saline and adjusting the $\mathrm{pH}$ to 5.0 with $5 \mathrm{M}$ sodium hydroxide. Immunoglobulin was concentrated from the Wellcome Streptococcal Grouping Sera by precipitation with 35\% ammonium sulphate. Group A serum was used at $2 \mathrm{mg} \mathrm{ml}^{-1}$ and groups $B$, $\mathrm{C}, \mathrm{D}, \mathrm{F}$ and $\mathrm{G}$ at $1.5 \mathrm{mg} \mathrm{ml}^{-1}$. The purified immunoglobulins were then coupled to sheep red cells in piperazine buffer. ${ }^{11}$ Optimal concentrations of coupling solution for groups A, $\mathrm{B}, \mathrm{D}, \mathrm{F}$ and $\mathrm{G}$ were 1 in 80 , and for group $\mathrm{C} 1$ in 100. Optimal coupling was confirmed by titration with anti-rabbit globulin. Samples $(1 \mathrm{ml})$ of coupled cells were stabilised with $100 \mu \mathrm{l}$ of glutaraldehyde (BDH; $30 \mu \mathrm{l}$ in $5 \mathrm{ml}$ PBS) and then freeze dried in PBS with $1.5 \%$ sucrose and $1.0 \%$ bovine serum albumin (Calbiochem, USA) in an Edward's Modulyo freeze dryer overnight. Before use cells were reconstituted with gentle mixing in PBS to their original volumes at $4^{\circ} \mathrm{C}$ for 24 hours; shorter reconstitution times gave weaker distinction between positive and negative results.

ISOLATION OF STREPTOCOCCI

In our diagnostic laboratory primary isolation 
plates growing presumptive $\beta$ haemolytic streptococci or enterococci are passed from all laboratory areas to a central "streptococcal bench" for confirmation by macroscopic examination of colonies and sometimes by Gram stain, Streptex grouping, and, if necessary, API 20 Strep testing. For the purposes of this study, specimens were classified as "skin" (surface swabs sent from general practitioners and the hospital dermatology department), "respiratory" (nose and throat swabs, and sputum), "genital", "urine", and "wound" (surface swabs, tissues, and aspirates from inpatients). Putative streptococci from urine were grouped off cysteinelactose-electrolyte-deficient agar (CM 301; Oxoid UK) and all other $\beta$ haemolytic isolates were grouped off bilayered blood agar plates, the top layer comprising $8 \mathrm{ml}$ heart infusion agar (0044-17; Difco, UK) with 10\% defibrinated horse blood and the bottom layer comprising $8 \mathrm{ml}$ Blood Agar Base No 2 (CM 271; Oxoid). Nine organisms submitted for grouping were recognised at this stage as being viridans streptococci or as belonging to other genera, but were grouped by both systems as additional controls.

\section{GROUPING OF STREPTOCOCCI}

Streptex grouping was performed by one of us (RW) using a modification of the manufacturer's recommendations on extracts from consecutive plates over a five week period. If possible, five or six colonies were picked from each primary plate, care being taken to minimise contamination from adjacent colonies, and emulsified in $0.2 \mathrm{ml}$ of extraction enzyme (ZL 55, Wellcome, diluted in $22 \mathrm{ml}$ distilled water) in Dreyer's tubes. There were incubated at $56^{\circ} \mathrm{C}$ for eight minutes, and six separate $0.02 \mathrm{ml}$ drops of the extracted supernatant were then transferred by a standard platinum loop to clean glass slides. Such scal- ing down of the quantities of reagent used has been reported to be reliable and economic. ${ }^{6}$ Latex and control reagents were added to the drops by the standard $0.02 \mathrm{ml}$ loop, mixed, the slides rocked, and agglutination read by eye usually within 20 seconds. Reactions were classified as strong or weak. Each batch of reagent was controlled against the manufacturer's positive control antigen before it was used.

The remainder of the extracts were passed daily to SW, who performed reverse passive haemagglutination without examining the primary culture plates and without knowing the results of Streptex grouping. Neat streptococcal extracts were diluted 1 in 8 with PBS containing $0.1 \%$ normal rabbit serum. Diluted extract $(30 \mu \mathrm{l})$ was mixed with $30 \mu \mathrm{l}$ of reconstituted red cells for each group in Aljen "V-well" microtitre plates (Aljen, Burgess Hill, Sussex; product code 100305). Sterlin (Hounslow, Middlesex; code 611V96), Dynatech (Billingshurst, Kent; code M25A Dynatech V), Nunc (Gibco, Paisley, Scotland; code 2-45128A) and Greiner (Dursley, England; code 651161) plates were also investigated for use in the assay, but the angle of the Aljen wells gave the best balance of quality between negative and positive reactions (figure). Eleven extracts were tested on each plate. One negative control well for each group was included on each plate, which contained buffer and coupled red cells but no organism extract. Plates were shaken to mix, and the result of haemagglutination was read by the sedimentation pattern after 45 minutes at room temperature. Additional readings were taken after a further 30 and 60 minutes at room temperature, and after overnight storage at $4^{\circ} \mathrm{C}$.

Extracts of 52 control organisms were prepared and tested by Streptex and reverse passive haemagglutination. Positive controls
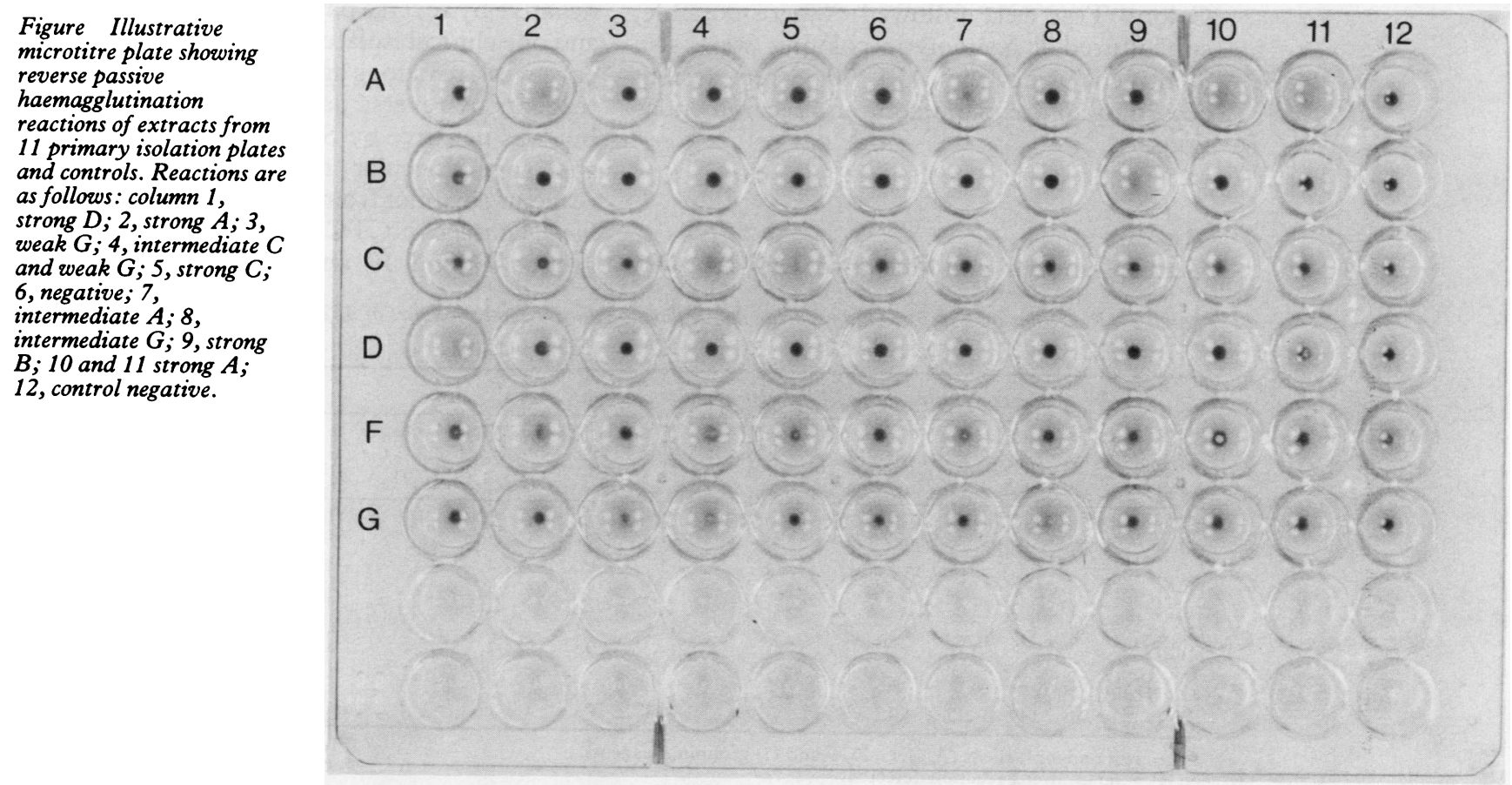
Table 1 Site of origin and Lancefield group of 338 streptococci with identical reverse passive haemagglutination and Streptex results

\begin{tabular}{|c|c|c|c|c|c|c|c|}
\hline \multirow[b]{2}{*}{ Site } & \multicolumn{6}{|c|}{ Group } & \multirow[b]{2}{*}{$t$} \\
\hline & $A$ & $B$ & $C$ & $D$ & $F$ & $G$ & \\
\hline $\begin{array}{l}\text { Skin } \\
\text { Respiratory } \\
\text { Genital } \\
\text { Urine } \\
\text { Wound } \\
t\end{array}$ & $\begin{array}{r}15^{\star} \\
126 \\
7 \\
0 \\
2 \\
150\end{array}$ & $\begin{array}{r}5 \\
3 \\
25 \\
8 \\
4 \\
45\end{array}$ & $\begin{array}{c}4^{\star} \\
12 \\
1 \\
0 \\
1 \\
18\end{array}$ & $\begin{array}{l}3^{\star} \\
0 \\
16 \\
45 \\
12 \\
76\end{array}$ & $\begin{array}{l}2 \\
1 \\
2 \\
0 \\
3 \\
8\end{array}$ & $\begin{array}{r}12 \\
13 \\
6 \\
1 \\
9 \\
41\end{array}$ & $\begin{array}{r}41 \\
155 \\
57 \\
54 \\
31 \\
338\end{array}$ \\
\hline
\end{tabular}

^Reactions with more than one antigen in both systems were confirmed in one extract to be due to a mixed culture of streptococci of groups $A$ and $C$, and in another to a mixture of groups $A$ and $\mathrm{D}$. tested from the 349 consecutive primary isolation plates. Nine of these extracts were negative in both systems and were confirmed not to be $\beta$ haemolytic streptococci or enterococci, and two of the remaining 343 extracts reacted with more than one grouping reagent in both systems. Discrepant results between Streptex and RPH were seen with seven extracts; the reference method, Streptex, identified 345 streptococci and reverse passive haemagglutination gave identical grouping results in $\mathbf{3 3 8}$ of these $(98.0 \%)$. Table 1 shows the distribution of these isolates by specimen of origin and Lancefield group.

All reverse passive haemagglutination control wells were negative. Three primary isolation plates (from one skin swab, one respiratory specimen, and one urine sample) contained mixed cultures of $\beta$ haemolytic streptococci before Streptex grouping was performed, and these isolates were submitted separately for Streptex and reverse passive haemagglutination grouping and are counted individually in table 1. Two extracts gave the same mixed reactions by both techniques (one groups $A$ and $\mathrm{C}$, one groups $\mathrm{A}$ and $\mathrm{D}$, both from skin swabs) and were confirmed to contain mixtures of these streptococci on subculture. Of the nine organisms found not be to $\beta$ haemolytic streptococci or enterococci, four were viridans streptococci (respiratory), three diphtheroids (one skin swab, two urine samples), one Haemophilus parainfluenzae (respiratory) and one a Gram negative rod (urine).

Table 2 correlates the reactions of each extract using the Streptex and reverse passive haemagglutination methods. The $\kappa$ coefficient of agreement between the two methods was high at $0.973 .^{912}$ Table 3 gives details of the seven extracts from seven primary isolation plates that gave discrepant grouping results.

Five anomalous results were obtained on testing the 39 control extracts. One clinical isolate of $P s$ aeruginosa gave weak positive reactions with all groups by Streptex but was negative by reverse passive haemagglutination, and one clinical isolate of Klebsiella pneumoniae gave weak reactions against group $\mathrm{C}, \mathrm{D}$, and $\mathrm{F}$ reagents by reverse passive haemagglutination but was negative by Streptex. Several Listeria spp gave floccular reactions with Streptex reagents, distinct from the usual granularity: $L$ monocytogenes NCTC 11994 was positive with groups $\mathrm{D}$ and $\mathrm{F}$, and weakly positive with

\section{Results}

grlutination techniques of 352 extracts from presumed

Table 2 Reactions by Streptex and reverse passive haemagglutination techniques of 352 extracts from presumed streptococci

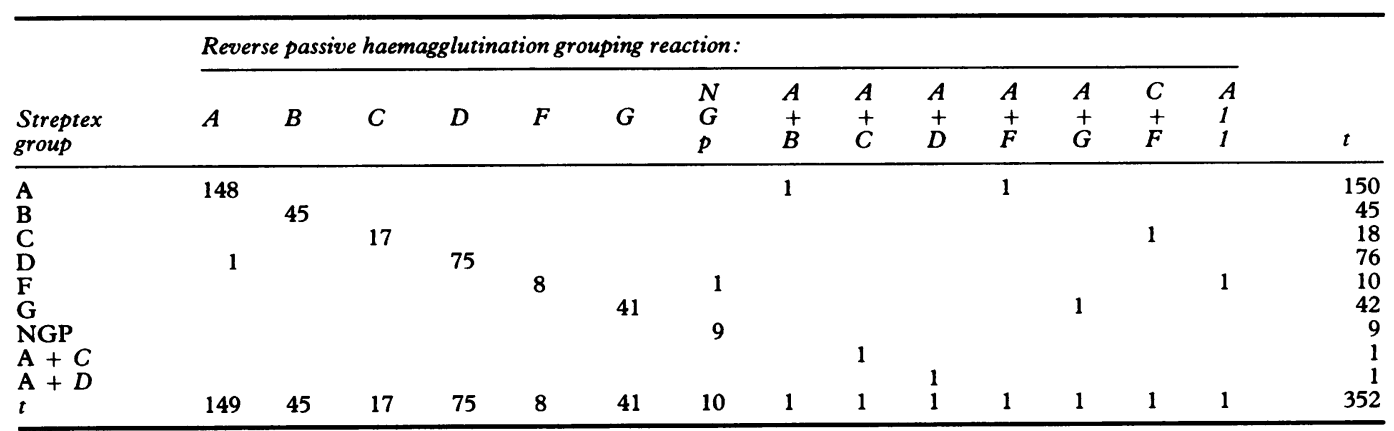

All $=$ reaction with all six $(A, B, C, D, F$ and $G)$ grouping reagents.

NGP = no grouping reaction detected. 
Table 3 Details of seven extracts with discrepant Streptex and reverse passive haemagglutination results, and results of investigation after subculture

\begin{tabular}{|c|c|c|c|c|c|}
\hline $\begin{array}{l}\text { Case } \\
\text { No }\end{array}$ & Site & Streptex & $R P H$ & Phadebact & Comment \\
\hline 1 & Skin & $\mathrm{C}+$ & \multirow{4}{*}{$\begin{array}{l}\mathrm{C}+1- \\
\mathrm{F}+1- \\
\mathrm{A}++ \\
\mathrm{B}+1- \\
\mathrm{G}+ \\
\mathrm{A}+1- \\
\mathrm{A}++ \\
\mathrm{F}+1-\end{array}$} & \multirow{3}{*}{$\begin{array}{l}\mathrm{C}+1- \\
\mathbf{F}+1- \\
\mathbf{A}+ \\
\mathbf{B}+1- \\
\mathbf{G}+\end{array}$} & \multirow{4}{*}{$\begin{array}{l}\text { Heavily mixed culture, No groups } \mathrm{C} \text { or } \mathrm{F} \\
\text { streptococci isolated on subculture } \\
\text { API Strep confirmed } S \text { pyogenes, } \\
\text { only group A streptococci isolated on subculture } \\
\text { API Strep confirmed group G streptococcus, } \\
\text { only group G streptococci isolated on subculture } \\
\text { API Strep confirmed } S \text { pyogenes, } \\
\text { heavily mixed primary culture, only group A } \\
\text { streptococci isolated on subculture }\end{array}$} \\
\hline 2 & Respiratory & $A+$ & & & \\
\hline 3 & Respiratory & $\mathrm{G}+$ & & & \\
\hline 4 & Genital & $A+$ & & $\begin{array}{l}\mathbf{A}+ \\
\mathbf{F}+1-\end{array}$ & \\
\hline $\begin{array}{l}5 \\
6\end{array}$ & $\begin{array}{l}\text { Urine } \\
\text { Wound }\end{array}$ & $\begin{array}{l}\mathrm{D}+ \\
\mathrm{F}+1-\end{array}$ & $\begin{array}{l}\mathrm{A}++ \\
\text { All }\end{array}$ & $\begin{array}{l}\text { ND } \\
\text { All } \\
+1-\end{array}$ & $\begin{array}{l}\text { Primary plate overgrown with Proteus sp } \\
\text { API strep confirmed } S \text { cremoris }\end{array}$ \\
\hline 7 & Wound & $\mathbf{F}+1-$ & - & ND & Organism died before further testing \\
\hline
\end{tabular}

Key:

Streptex and Phadebact reaction strength: + strong; + / - weak.

RPH reaction strength: + + strong; + intermediate; + / - weak; - negative.

All: positive reactions with groups A, B, C, D, F and G.

ND: not done.

groups A, C and G; NCTC 10887 was positive with group $\mathrm{D}$ and weakly so with groups $\mathrm{A}$ and C. L innocua (DMRQC) was positive with groups D and F and weakly so with group $G$, and NCTC 11288 was weakly positive with group C. $L$ seeligeri gave a weak group D reaction. L monocytogenes NCTC 11994 also gave floccular positive reactions with all Phadebact reagents, but no other discrepancies were seen using this techique. Reactions of $S$ anginosus (group $\mathrm{G}$ ) and group $\mathrm{F}$ streptococcus NCTC 5389 were strong in both reverse passive haemagglutination and Phadebact tests, but weak by Streptex. Negative controls gave negative reactions throughout.

Reverse passive haemagglutination reactions are generally easy to read and classify, but because of the different characteristic reactions of each grouping reagent we found it important to compare reactions horizontally with others of the same group rather than vertically between different groups (figure). Considering only the 345 extracts that did not give discrepant reactions with Streptex, the following percentages of reverse passive haemagglutination reactions were strong or intermediate at 45, 75 and 105 minutes and overnight: $98 \cdot 6$, $84 \cdot 7,73 \cdot 4$ and $67 \cdot 4$ for group $A ; 82 \cdot 2,71 \cdot 1,71 \cdot 1$ and 64.5 for group B; $100,88.9,88.9$ and 77.9 for group $C ; 81 \cdot 6,68 \cdot 4,63 \cdot 2$ and $55 \cdot 2$ for group D; $87.5,75.0,75.0$ and 75.0 for group $F$ and $75 \cdot 6,31 \cdot 7,22 \cdot 0$ and $9 \cdot 7$ for group $G$.

No weakly positive reactions were seen with group A, B, C and D Streptex reagents, but six of 10 reactions $(60 \%)$ with the group $F$ reagent and two of $42(4 \cdot 8 \%)$ with group $G$ were weak.

According to the reverse passive haemagglutination methods we used, positive controls for each group could readily be included on every plate, and it would also be possible to test extracts against freeze-dried red cells coupled to rabbit non-specific polyclonal antibody as an additional negative control. There were sufficient wells to have included four more test organisms, but clarity and ease of comparison would be reduced.

After the extracts had been received the technical time to set up and read these 11 tests was about 25 minutes (including reconstitution of reagents, dilution of extracts, inoculation of wells and reading of the plate). This compares with about 66 minutes for 11 organisms tested against all six antisera by Streptex.

\section{Discussion}

The results of streptococcal grouping should be available quickly, preferably within 24 hours of submission of the specimen if they are to have the best chance of influencing clinical management. This implies that grouping tests must be carried out on colonies from primary isolation plates as they were in this study, unless direct antigen detection is performed on clinical material.

There was a high degree of agreement between the grouping reactions of reverse passive haemagglutination and Streptex. This was despite reverse passive haemagglutination testing being performed blind of the colonial appearances on the primary plate, with some extracts containing antigens from contaminating bacteria. Ninety eight per cent of streptococci grouped by Streptex gave indentical results by reverse passive haemagglutination. The $\kappa$ coefficient of agreement of 0.973 between both methods was higher than that $(0.958)$ previously reported in a comparison between a latex agglutination kit and a traditional Lancefield grouping method. ${ }^{9}$ This coefficient measures the proportion of times two methods agree compared with the maximum possible number of times they could agree, corrected for chance agreement. ${ }^{12} \mathrm{We}$ did not use Lancefield grouping as a reference because it is not applicable to mixed primary isolation plates, and we wished to compare methods currently available to a clinical diagnostic laboratory.

Determinants of the specificity and sensitivity of the available serological grouping methods include the quantity of streptococcal cells assayed, the adequacy of any antigen extraction method used (which may vary for streptococci of different groups ${ }^{13}$ ), the inactivation of protein A-like substances, ${ }^{14}$ details of suspension media ${ }^{5}$ and the presence of crossreacting antigens derived from other flora on the plate, ${ }^{815}$ which may not be epitope specific. These factors may be adversely affected if grouping is done from primary isolation media, ${ }^{2-48916}$ and the best correlations between rapid and reference methods have been ob- 
tained when overnight pure broth cultures have been used, ${ }^{3}$ or when the manufacturer's recommendations for the numbers of colonies to be extracted have been exceeded. ${ }^{2}$ Nevertheless, the resulting cross reactions are usually weak and in experienced hands rarely result in incorrect grouping by the Streptex kit. ${ }^{6}$ Some authors have applied direct grouping from primary plates selectively to those cultures with large numbers of easily separable colonies. ${ }^{8}$

Extraction procedures have been modified in several ways for increased speed, but coagglutination methods have the advantage that extraction may not be required, presumably because the Fc portions of group specific antibodies are bound to the carrier staphylococci and are not available for cross reaction to protein A-like substances on group A, C, and $\mathrm{G}$ streptococci. ${ }^{14}$

Of the seven extracts that gave discrepant results (table 3), four were due to additional reactions to other groups in reverse passive haemagglutination. In three of these Phadebact also gave the same reaction, and in two the extracts came from heavily mixed cultures. Small amounts of Lancefield antigen from streptococci or other species might have been present in these extracts, or non-epitopespecific cross reactions might have occurred to immunoglobulins or red cells. The strong reaction with group D Streptex of one extract that gave a strong group A reaction with reverse passive haemagglutination may have been due to a true difference in reactivity, to splash-over between wells on the reverse passive haemagglutination microtitre plate, or to a transcription error, but confirmation of this was not possible because the primary plate had been heavily overgrown with Proteus sp. There were extracts with strong group A reactions on this microtitre plate, but they were not immediately adjacent to the extract in question. The weak reaction with all groups by reverse passive haemagglutination seen with one $S$ cremoris isolate from an infected abdominal surgical wound, which normally carries the group $\mathrm{N}$ antigen, ${ }^{17}$ would be clinically less confusing than the group $F$ reaction observed in the Streptex system.

Cross reactions between Streptex reagents and $L$ monocytogenes have been reported, ${ }^{15}$ but were not noted to be floccular and were most commonly against group B reagents. We observed floccular reactions with $L$ monocytogenes against all groups except $B$, and also found strains of $L$ seeligeri and innocua to give cross reactions. MacGowan et al suggested that these problems may be due to rhamnose determinants shared between streptococcal polysaccharides and listerial $O$ antigens, ${ }^{15}$ but non-epitope-specific reactions to bound immunoglobulins or carrier particles were not excluded. This may explain the lack of cross reactivity in the reverse passive haemagglutination system.

Strong or intermediate positive reactions in reverse passive haemagglutination persisted well for at least 30 minutes after the conventional reading interval of 45 minutes. Checking of results by other staff in a clinical laboratory would therefore be possible. All extracts tested except one (group F by Streptex) were groupable by reverse passive haemagglutination, but group G strains gave the weakest reverse passive haemagglutination reactions with only three quarters classified as strong or intermediate. Such differences are likely to be due to batch variation in antibody reactivity, or in coupling to the red cell carrier. In common with our experience, others have reported group F reactions in the Streptex system to be weak: Keville and Doern found $41 \%$ of such strains to be ungroupable after enzyme extraction from pure subcultures. ${ }^{18}$ In reverse passive haemagglutination we used only single batches of each antibody, but we did find some interbatch variation among successive couplings (data not shown). The reactions of each reverse passive haemagglutination grouping reagent were consistent, but qualitative differences were observed between groups (figure). Part of this variation could probably be avoided and the strength of group $G$ reactions improved by further modifications to the coupling or freezedrying procedures, and for routine laboratory use it would be helpful to include positive as well as negative controls for each group on every plate.

Batch processing of extracts would be a major potential advantage of a streptococcal grouping system based on reverse passive haemagglutination, and considerable savings of time would result for laboratories grouping large numbers of organisms. Centralised grouping in one laboratory area has the disadvantage of separating the initial recognition of a streptococcus from its final confirmation, and reorganisation of work would be needed in many laboratories, but standardisation should improve and quality control be simplified.

We are grateful to RRA Coombs, Emeritus Professor, University of Cambridge, for helpful discussion and encouragement, and to the East Anglian Regional Health Authority Research Committee for their support.

1 Facklam RR, Carey RB. Streptococci and aerococci. In: Lennette EH, Balows A, Hausler WJ, Shadomy HJ, eds. Manual of clinical microbiology. Washington, DC: American Society for Microbiology, 1985:154-75.

2 Facklam RR, Cooksey RC, Wortham EC. Evaluation of commercial latex agglutination reagents for grouping streptococci. J Clin Microbiol 1979;10:641-6.

3 Slifkin M, Pouchet-Melvin GR. Evaluation of three commercially available test products for serogrouping betahemolytic streptococci. J Clin Microbiol 1980;11:249-55.

4 Silfkin M, Interval G. Serogrouping single colonies of betahemolytic streptococci from primary throat culture plates with nitrous acid extraction and Phadebact streptococcal with nitrous acid extraction and Phadebact

5 Engel HWB, Slifhout A. Simplified coagglutination test for serological grouping of beta-haemolytic streptococci.
J Clin Microbiol 1981;14:252-5.

6 Castle D, Kessock-Philip S, Easmon CSF. Evaluation of an improved Streptex kit for the grouping of betahaemolytic streptococci by agglutination. J Clin Pathol 1982;35:719-22.

7 Keville MW, Doern DV. Comparison of the API 20 S Streptococcus identification system with an immunorheophoresis procedure and two commercial latex agglutination tests for identifying beta-haemolytic streptococci. J Clin Microbiol 1982;16:92-5.

8 Hamilton JR. Comparison of Meritec-Strep with Streptex for direct colony grouping of beta-hemolytic streptococci from primary isolation and subculture plates. J Clin Microbiol 1988;26:692-5.

9 Beck R, Etzion R, Sandler S, Kohn L. Evaluation of the rapid Patho Dx Latex Strep Grouping Kit. J Clin Microbiol 1990;28:398-9.

10 Coombs RRA. Harnessing the red cell for immunoassays. Med Lab Sci 1987;44:66-72. 
11 Coombs RRA, Scott ML, Cranage MP. Assays using red cell-labelled antibodies. $J$ Immunol Methods 1987;101: $1-14$.

12 Cohen J. A coefficient of agreement for nominal scales. Educational and Psychological Measurement 1960;20: $37-46$.

13 Maxted WR. Preparation of streptococcal extracts for Lancefield grouping. Lancet 1948;ii:255-6.

14 Freimer EH, Raeder R, Feinstein A, Herbert J, Gurner BW, Coombs RRA. Detection of protein A-like substances on haemolytic streptococci prior to use in mixed revers passive antiglobulin haemagglutination $\left(\mathrm{M}_{R} \mathrm{PAH}\right)$. J
Immunol Methods 1979;31:219-29.

15 MacGowan A, Marshall R, Reeves D. False-positive reactions with Listeria monocytogenes using a commercial kit for Lancefield grouping of beta-haemolytic streptococci. Eur J Clin Microbiol Infect Dis 1988;7:208-10.

16 Bixler-Forell EW, Martin WJ, Moody MD. Clinical evaluation of the improved Streptex method for grouping streptococci. Diagn Microbiol Infect Dis 1984;2:113-8.

17 Colman G. Streptococcus and Lactobacillus. In: Parker MT, Duerden BI, eds. Principles of bacteriology, virology
MT MT, Duerden BI, eds. Principles of bacteriology, virology
and immunity. Volume 2. London: Edward Arnold, 1990: and immum $119-59$.

\section{Eponyms in pathology ...}

LEISHMAN, Sir William Boog (18651926) was a British microbiologist. Born in Glasgow, he studied medicine, graduating in 1886. He joined the RAMC in 1887 and after a brief period in India, he returned to the AMS in Netley, succeeding Sir Almroth Wright as professor of pathology in 1900. After the First World War he became director of pathology at the war office and eventually director general of the army medical services in 1923. In 1903 he described the causal organism of kala azar, Leishmania donovani, as well as the intracellular non-flagellate forms of the parasite now called Leishman-Donovan bodies. He was knighted in 1909, elected an FRS in 1910, and rose to the rank of lieutenant-general in 1923.
LANGHANS, Theodor (1839-1915) was a German pathologist born in Usingen. He trained in Wurzburg, central Germany, qualifying in 1864, and served as professor of pathological anatomy at Giessen (1868) and later in Berne (1872). He described the characteristic multinucleate giant cells of tuberculous lesions in 1867. 